\title{
Th17 Response and Inflammatory Autoimmune Diseases
}

\author{
Janelle C. Waite and Dimitris Skokos \\ Department of Immunity and Inflammation, Regeneron Pharmaceuticals, Inc., 777 Old Saw Mill River Road, \\ Tarrytown, NY 10591, USA
}

Correspondence should be addressed to Dimitris Skokos, dimitris.skokos@regeneron.com

Received 12 August 2011; Accepted 27 October 2011

Academic Editor: Petros Efthimiou

Copyright ( $) 2012$ J. C. Waite and D. Skokos. This is an open access article distributed under the Creative Commons Attribution License, which permits unrestricted use, distribution, and reproduction in any medium, provided the original work is properly cited.

\begin{abstract}
The proinflammatory activity of T helper 17 (Th17) cells can be beneficial to the host during infection. However, uncontrolled or inappropriate Th17 activation has been linked to several autoimmune and autoinflammatory pathologies. Indeed, preclinical and clinical data show that Th17 cells are associated with several autoimmune diseases such as arthritis, multiple sclerosis, psoriasis, and lupus. Furthermore, targeting the interleukin-17 (IL-17) pathway has attenuated disease severity in preclinical models of autoimmune diseases. Interestingly, a recent report brings to light a potential role for Th17 cells in the autoinflammatory disorder adult-onset Still's disease (AOSD). Whether Th17 cells are the cause or are directly involved in AOSD remains to be shown. In this paper, we discuss the biology of Th17 cells, their role in autoimmune disease development, and in AOSD in particular, as well as the growing interest of the pharmaceutical industry in their use as therapeutic targets.
\end{abstract}

\section{Th17 Cell Differentiation}

Th17 cells are a novel class of helper $\mathrm{CD} 4^{+} \mathrm{T}$ cells described in 2005 that secrete IL-17A, IL-17F, IL-21, and IL-22 [1-3]. Differentiation of naïve $\mathrm{T}$ cells towards a Th17 phenotype is supported by several cytokines including transforming growth factor- $\beta$ (TGF- $\beta$ ), IL- $1 \beta$, IL-6, IL-21, and IL-23 in mice and humans [4-8]. Indeed, ligation of toll-like receptors TLR3, TLR4, or TLR9 induces secretion of TGF- $\beta$ and IL-6 that subsequently supports de novo differentiation of naïve $\mathrm{CD}^{+} \mathrm{T}$ cells to Th17, cells in vitro [9]. Further, it has been shown that TGF $\beta$ is required for the initiation of Th17 dependent autoimmune encephalitis in vivo [10]. TGF$\beta$ prevents Th1 and Th2 differentiation by suppressing Stat 4 and GATA-3 expression, thus allowing Th17 differentiation; however, Th17 development also occurs in the absence of TGF- $\beta$ signaling $[11,12]$. In an elegant study, Ivanov et al. demonstrated that TGF $\beta$ and IL- 6 promote IL-21R and IL$23 \mathrm{R}$ expression by a mechanism implicating $\mathrm{ROR} \gamma \mathrm{T}$ [13]. Moreover, IL-21 expression by Th17 cells acts in an autocrine manner to promote Th17 differentiation [14, 15], while increased expression of IL-23R expression downstream of Tcell activation and Th17 development allows IL-23 signaling to further maintain Th17 activity in a Stat3-dependent manner $[4,16]$. Furthermore, IL-18 synergizes with IL-23 to promote IL-17 production by IL-23-primed CD4 ${ }^{+} \mathrm{T}$ cells [17]. IL-18 was also shown to induce the ex vivo release of IL-17 and IL-23 from lymphocytes of systemic lupus erythematosus (SLE) patients [18]. It is well established that IL-18 is an important cytokine implicated in promoting Th1 polarization, which is characterized by interferon (IFN- $\gamma$ ) release. IFN- $\gamma$ secretion subsequently activates both neutrophils and macrophages, resulting in the intracellular killing of bacteria and fungi [19]. In contrast, IL- $1 \beta$ negatively regulates Th1 differentiation by inducing cyclooxygenase (COX)-2, which subsequently increases the secretion of prostaglandin E2 (PGE2) that suppresses IFN- $\gamma$ production [20] thus allowing Th17 differentiation. Indeed, IL- $1 \beta$ has been shown to enhance Th17 responses in the presence of IL-23 [4, 7]. While further investigation is needed to better understand the biology of Th17 differentiation and the parameters involved in this process, overall the above studies shed light and reveal the complexity of this pathway (summarized in Figure 1).

\section{IL-17: Expression and Function}

IL-17 is a potent proinflammatory cytokine that amplifies ongoing inflammation by inducing expression of tumor 


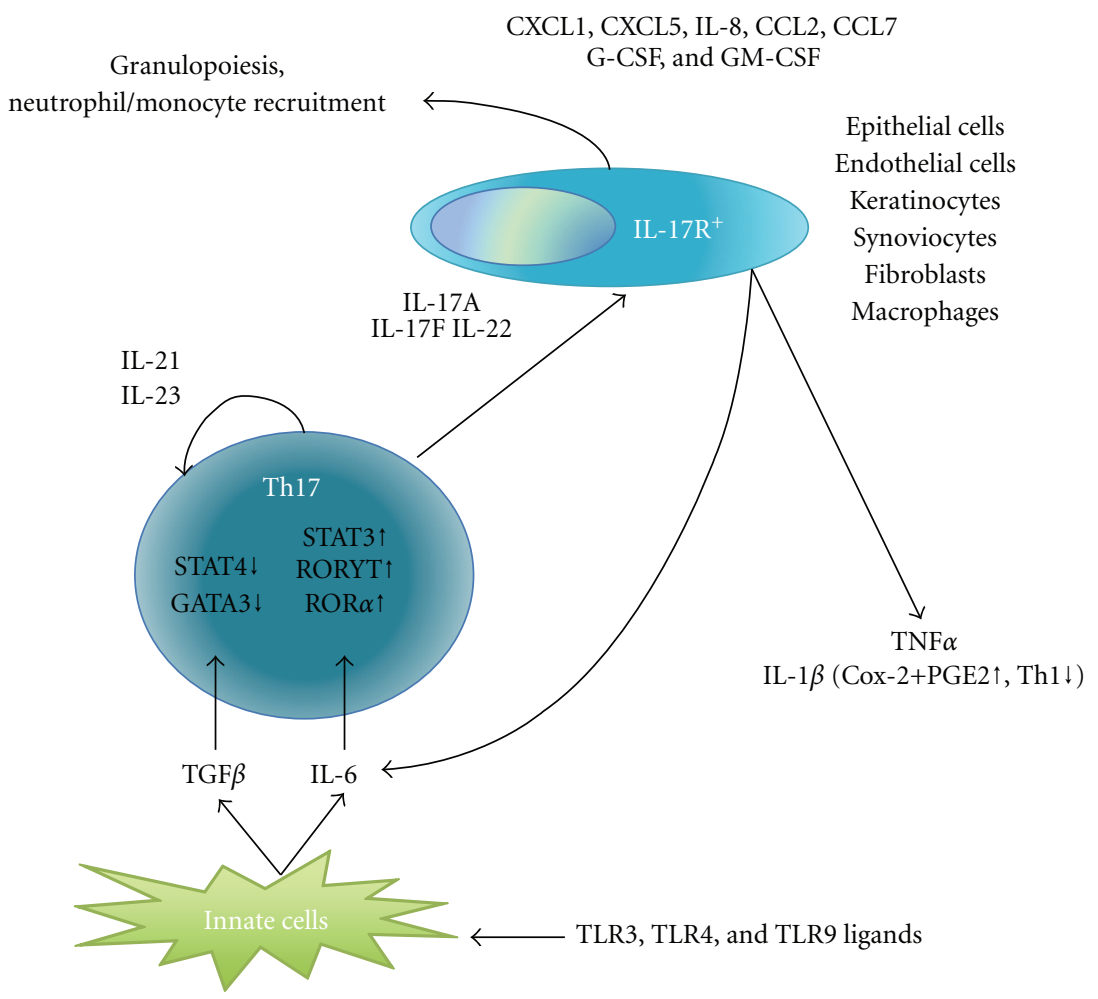

FIGURE 1: Implications of Th17 differentiation in the development of the immune response.

necrosis factor- $\alpha$ (TNF- $\alpha$ ), IL- $1 \beta$, and IL-6 in epithelial and endothelial cells as well as other cell types such as keratinocytes, synoviocytes, fibroblasts, and macrophages. IL-17, also known as IL-17A, is the founding member of the structurally related IL-17 family, which includes IL17B, IL-17C, IL-17D, IL-17E (also called IL-25), and IL17F. IL-17F shares the highest amino acid identity with IL17A [21]. The IL-17 receptor family also has five members with conserved extracellular fibronectin III-like domains and cytoplasmic "similar expression to FGF/IL-17R" (SEFIR) domains [22]. IL-17 receptor expression profiles show that IL-17RA and IL-17RC are present in different cell types and tissues. Immune cells mostly express IL-17RA, while IL-17RC is found on the surface of epithelial cells and fibroblasts [23, 24]. Upon engagement, IL-17R signaling activates NF- $\kappa B$, MAPK, and C/EBP pathways via SEFIR domain containing the adaptor protein Act1. Act1 further interacts with TRAF6 and TAK1 to promote signal transduction and cytokine and chemokine secretion [25]. Indeed, IL-17 stimulates production of chemokines such as CXCL1, CXCL5, IL-8, CCL2, and CCL7 that are responsible for recruitment of neutrophils to the site of inflammation [26]. For example, local production of IL-17 by $\mathrm{Th}_{17}{ }^{+}$cells in the central nervous system (CNS) promotes neutrophil recruitment in a mouse model of multiple sclerosis (MS), experimental autoimmune encephalomyelitis (EAE) $[3,10]$. Furthermore, IL-17 enhances granulopoiesis by triggering expression of GCSF and GM-CSF [27-29]. Although GM-CSF expression is not required for Th17 differentiation, a recent study showed that this cytokine is required for autoimmune neuroinflammation via myeloid cells $\left(\mathrm{CD} 45^{\mathrm{hi}}, \mathrm{CD} 11 \mathrm{~b}^{+}\right)$ infiltrating the central nervous system during the effector phase of the response $[30,31]$.

\section{Th17 Cells and Microbial Immunity}

Th17 cells play an important role in host defense against bacterial and fungal infection, especially at mucosal surfaces. Production of IL-17 and IL-22 upon Th17 cell triggering improves mucosal barrier surfaces by stimulating release of antimicrobial peptides and recruiting neutrophils. However, in viral and parasitic infections, Th17 responses can be detrimental to the host. During Theiler's murine encephalomyelitis virus (TMEV) infection, anti-IL-17 treatment inhibits viral persistence and development of demyelinating disease [32]. Further, it was demonstrated in this study that in vitro treatment of bone marrow (BM) cells or astrocytes with recombinant IL-17 increases expression of antiapoptotic molecules $\mathrm{Bcl}-\mathrm{xl}$ and $\mathrm{Bcl}-2$, thus preventing destruction by cytotoxic $\mathrm{T}$ cells. This results in persistence of the infection by enhancing the survival of virus-infected cells. In addition, it has been shown that pretreatment of target cells (coated with viral peptide) with IL-17 reduced their susceptibility to cytolytic killing by $\mathrm{CD}^{+} \mathrm{T}$ cells. In contrast, pretreatment of $\mathrm{CD}^{+} \mathrm{T}$ cells does not affect cytotoxicity. These results indicate that IL-17 alters the susceptibility of the target cell to apoptosis rather than the effector T cell's ability to kill infected cells. In vivo experiments using TMEV-infected mice treated with anti-IL-17 antibody showed that IL-17 blockade enhances viral load and reduces expression of prosurvival 
TABLE 1: Preclinical mouse models showing a role for Th17 cells and the IL-17 pathway in autoimmunity.

\begin{tabular}{|c|c|c|c|}
\hline Disease & Model & Role of Th17 & Reference \\
\hline \multirow{5}{*}{ Rheumatoid arthritis } & Collagen-induced arthritis (CIA) & $\begin{array}{l}\text { IL-23 (p19 subunit) KO mice have less Th17 cells and reduced } \\
\text { disease severity }\end{array}$ & {$[35]$} \\
\hline & Collagen-induced arthritis (CIA) & IL-17A KO mice have reduced disease incidence and severity & {$[36]$} \\
\hline & $\begin{array}{l}\text { IL-6R subunit gp130 (Y759F) } \\
\text { mutation }\end{array}$ & $\begin{array}{l}\text { Enforced IL-6 expression enhances disease progression in an } \\
\text { IL-17A-dependent manner }\end{array}$ & {$[37]$} \\
\hline & SKG-dominant active ZAP70 mutant & IL-17A KO mice are resistant to arthritis & {$[39]$} \\
\hline & HTLV-I Tg mice & IL-17A KO mice are resistant to arthritis & {$[41]$} \\
\hline \multirow{4}{*}{$\begin{array}{l}\text { Inflammatory Bowel } \\
\text { disease }\end{array}$} & $\begin{array}{l}\text { Adoptive transfer of } \mathrm{CD}^{+} \mathrm{CD} 45 \mathrm{RB}^{\mathrm{hi}} \\
\text { cells to lymphopenic mice }\end{array}$ & $\begin{array}{l}\text { IL-17A KO CD4 }{ }^{+} \mathrm{T} \text { cells accelerated T-cell-mediated intestinal } \\
\text { damage }\end{array}$ & {$[42]$} \\
\hline & $\begin{array}{l}\text { Adoptive transfer of } \mathrm{CD} 4^{+} \mathrm{CD} 45 \mathrm{RB}^{\mathrm{hi}} \\
\text { cells to lymphopenic mice }\end{array}$ & $\begin{array}{l}\text { IL-17A, IL-17F, or IL-22 KO T-cells-induced colitis equally } \\
\text { compared to WT }\end{array}$ & {$[43]$} \\
\hline & Dextran sodium sulfate (DSS) & $\begin{array}{l}\text { IL-17F KO or IL-17A KO or mice treated with an anti-IL-17A } \\
\text { antibody showed severe weight loss and colonic epithelial } \\
\text { damage }\end{array}$ & {$[44,45]$} \\
\hline & Dextran sodium sulfate (DSS) & $\begin{array}{l}\text { IL-17A KO showed substantially reduced colitis based on both } \\
\text { clinical score and mortality }\end{array}$ & {$[46]$} \\
\hline \multirow{3}{*}{ Psoriasis } & $\begin{array}{l}\text { Topical application of imiquimod } \\
\text { (IMQ) }\end{array}$ & Dermatitis is blocked in IL-23R KO and IL-17R KO mice & {$[53]$} \\
\hline & IL-23 injection & $\begin{array}{l}\text { IL-6-dependent accumulation of Th17 cells in psoriatic skin, } \\
\text { dermatitis was greatly reduced in IL- } 22 \mathrm{KO} \text { or IL-17A KO mice }\end{array}$ & {$[55,56]$} \\
\hline & K5.Stat3C transgenic mice & $\begin{array}{l}\text { Constitutively express activated Stat } 3 \text { within keratinocytes } \\
\text { promotes Th17 cells, and anti-IL-23 was shown to block } \\
\text { epidermal hyperplasia; however, anti-IL-17 had only partial } \\
\text { effect }\end{array}$ & {$[57]$} \\
\hline \multirow[t]{2}{*}{ Type 1 diabetes } & $\begin{array}{l}\text { RIP-OVA mice (mice expressing OVA } \\
\text { peptide in pancreatic beta islet cells ) }\end{array}$ & $\begin{array}{l}\text { IL-17 producing } \mathrm{CD} 8^{+} \mathrm{T} \text { cells }(\mathrm{Tc} 17) \text { cause diabetes in an } \\
\text { IL-17A- and IL-17F-dependent manner when adoptively } \\
\text { transferred to RIP-OVA mice }\end{array}$ & {$[59]$} \\
\hline & Nonobese diabetes (NOD) & $\begin{array}{l}\text { Anti-IL-17A antibodies inhibit diabetes during the effector } \\
\text { phase of disease (at } 10 \text { weeks of age) but not during the } \\
\text { initiation of disease (mice less than } 5 \text { weeks of age) }\end{array}$ & {$[60]$} \\
\hline
\end{tabular}

$\mathrm{Bcl}-\mathrm{xl}$ and $\mathrm{Bcl}-2$ proteins in both infiltrating macrophages and resident microglia. This antibody treatment significantly increases the elimination of newly introduced viral epitope peptide-loaded target cells. Altogether, these findings suggest that IL-17 expression promotes viral persistence by inhibiting apoptosis of virally infected cells.

Moreover, in parasitic infection, IL-27R-deficient mice infected with Toxoplasma gondii develop severe neuroinflammation that is characterized by prominent IL-17 response [33]. When infected with Leishmania major, mice lacking IL-27R develop more severe lesions that are associated with the presence of $\mathrm{IL}-17^{+} \mathrm{CD} 4^{+}$cells [34]. Overall, these experiments suggest that the inappropriate development of Th17 cells in some infections could lead to increased disease progression and chronic infection rather than remission and microbe clearance.

\section{Th17 Cells in Preclinical Models of Autoimmunity}

4.1. Rheumatoid Arthritis (RA). Several mouse models exist for studying the mechanism of RA development. In these models, genetic inactivation of IL-17A or IL-17F has shown that Th17 cells do play a role in disease progression (summarized in Table 1).

In the collagen-induced arthritis (CIA) model, injection of type II collagen (CII) together with Complete Freud's adjuvant (CFA) containing heat-killed Mycobacterium tuberculosis triggers cell-mediated and humoral responses characterized by cellular infiltration and synovitis of the joints, resulting in swelling of the paws and progressive destruction of bone and cartilage. Disease is detected by measuring CIIspecific antibody levels in the serum. It has been shown that mice deficient in IL-23 (p19 subunit) show reduced 
numbers of IL- $17^{+}$cells in the draining lymph nodes and have less severe disease than mice lacking IL-12 (p35 subunit) [35]. In the same model, disease incidence and severity are greatly attenuated in IL-17A KO mice [36]. Further, IL$17 \mathrm{~A}$ and IL-17F double $\mathrm{KO}$ mice do not show additional disease suppression, indicating that IL-17F does not have any additive or synergistic effect [23]. These data suggest that IL-23-dependent Th17 function and production of IL17 support arthritis disease development.

Mice with a mutation in the gp130 subunit of IL-6R (Y759F) have disrupted SOCS3-mediated negative feedback and develop spontaneous arthritis as assessed by degree of swelling in the joints. In this model, increased IL-6 expression via hydrodynamics-based transfection enhances disease progression in an IL-17A-dependent manner [37]. IL-17Adeficient mice were resistant to arthritis while elevated IL-17 expression induced arthritis. Interestingly, IL-6 was required for IL-17A-induced arthritis, in Y759F mutants. These findings suggest that a positive feedback loop of IL-6 and IL-17 secretion is active in arthritis.

Mice with an activating mutation in the $\mathrm{SH} 2$ domain of ZAP-70, a key signal transduction molecule in T cells, spontaneously develop T-cell-mediated chronic autoimmune arthritis [38]. These so-called SKG mice develop autoreactive $\mathrm{T}$ cells due to defective negative selection in the thymus. In this model, arthritis is suppressed in the absence of IL-17A [39], suggesting that the pathogenic T cells are indeed Th17 ${ }^{+}$ cells.

Further, transgenic mice carrying the human T-cell leukemia virus type I (HTLV-1) tax gene with its own LTR promoter (HTLV-I Tg mice) develop chronic inflammatory polyarthropathy that resembles RA in humans [40]. This model is dependent on IL- $1 \alpha / \beta$ and IL- 6 and was recently shown to be dependent on IL-17A, as IL-17A KO mice are resistant to arthritis [41].

4.2. Inflammatory Bowel Disease and Crohn's Disease. The roles of Th17 cells in inflammatory bowel disease (IBD) and Crohn's Disease (CD) are somewhat more controversial than in other autoimmune diseases. Th17 cells were studied in a model for IBD, where naïve $\mathrm{CD} 4{ }^{+} \mathrm{CD} 45 \mathrm{RB}{ }^{\text {hi }}$ cells adoptively transferred to lymphopenic mice cause colitis characterized by weight loss, diarrhea, and histological analysis (degree of epithelial hyperplasia and goblet cell depletion, leukocyte infiltration in the lamina propria, area of tissue affected, crypt abscesses, submucosal inflammation, and ulcers). Indeed, IL-17A KO CD4 ${ }^{+}$T cells accelerated T-cell-mediated intestinal damage compared to wild-type (WT) $\mathrm{CD}^{+}{ }^{+} \mathrm{T}$ cells [42]. IL-17A KO T cells displayed increased IFN $\gamma$ production, suggesting that IL-17A can downregulate Th1 response and potentially protect against Th1-mediated tissue damage. However, this finding is controversial as another group using the same model showed that IL-17A, IL-17F, or IL-22 KO T cells induced colitis equally compared to WT T cells [43]. Treatment of mice upon adoptive transfer of IL-17F KO T cells with a neutralizing anti-IL-17A antibody significantly suppressed disease, indicating that IL-17A and IL-17F have redundant biological effects.
Additional models of IBD used to investigate the role of Th17 cells give mixed results as well. In the dextransodium-sulfate- (DSS-) induced colitis model, in which disease progression is primarily due to increased neutrophilic infiltration of the inflamed tissue, mice lacking IL-17F or IL-17A or mice treated with an anti-IL-17A antibody show severe weight loss and colonic epithelial damage [44, 45]. Conversely, a different study reported that genetic inactivation of IL-17A substantially reduces colitis based on both clinical score and mortality compared to WT animals, suggesting that IL-17 promotes colitis [46]. In this study, G-CSF and MCP-1 are reduced in DSS-treated IL-17A KO mice compared to treated WT mice. The disparities in these studies may be due to different intestinal microbial flora that affects the immune response in this disease model. Interestingly, IL-22 expression by CD4 ${ }^{+} \mathrm{T}$ cells and NK cells also has a protective role in both the DSS and T cell transfer models, as transfer of $\mathrm{T}$ cells from IL-22-deficient mice worsens disease [47].

It has recently been shown that during intestinal inflammation induced by anti-CD3 treatment, pathogenic Th17 cells in the gut express IL-10 receptor (IL-10R) and are negatively regulated by Foxp $3^{-}$and Foxp $3^{+}$Tregs in an IL10 -dependent manner [48]. IL-10R expression is required for Tregs to maintain sufficient IL-10 production and mediate inhibition of Th17 cells [49]. Paradoxically, Treg depletion in Foxp3-DTR mice may result in a reduced frequency of antigen-specific IL-17 producers in draining lymph nodes and blood and is correlated with reduced inflammatory skin responses during Candida albicans infection. This is likely mediated by a regulation of IL-2 availability $[50,51]$.

4.3. Psoriasis. IL-17 ${ }^{+} \mathrm{T}$ cells are increased in the dermis of psoriatic skin lesions [52]. In mice, topical application of imiquimod (IMQ), a TLR7/8 ligand, induces psoriasis-like dermatitis characterized by increased epidermal cell proliferation, neutrophil accumulation, and $\mathrm{CD} 4^{+} \mathrm{T}$ cell infiltration [53]. In this model, IMQ induces IL-23, IL-17A, and IL$17 \mathrm{E}$ expression in the epidermis and increased Th17 cells in the spleen. Furthermore, dermatitis is almost completely blocked in mice deficient in IL-23R and IL-17R. Psoriasislike epidermal hyperplasia can be induced in the ears of mice by directly injecting IL-23 [54] and was shown to be IL-6 dependent [55]. In IL-23 induced psoriasis, CCR6 ${ }^{+} \mathrm{Th}^{+} 7^{+}$ cells accumulate in psoriatic skin where CCL20 (the CCR6 ligand) expression is abundant. Comparison of CCR6 KO and WT mice confirmed that CCR6 expression was required for IL-23-induced dermatitis. IL-22 and IL-17A are also necessary for epidermal hyperplasia in this model, as dermatitis was greatly reduced in IL-22 KO or IL-17A KO mice [56]. Further, K5.Stat3C transgenic mice constitutively express activated Stat3 within keratinocytes and develop skin lesions with histological and cytokine profiles similar to those seen in human psoriasis [57]. In this model, antiIL-23 antibody treatment blocks epidermal hyperplasia and lowers transcript levels of Th17 cytokines (IL-17 and IL22), $\beta$-defensins, and S100A. However, blocking IL-17 with anti-IL-17 antibodies or using genetic inactivation models only moderately reduced psoriasis. Overall, these findings 
show that IL-23-mediated induction of IL-17 secretion and Th $17^{+}$recruitment in the inflamed tissue efficiently promote dermatitis; however, IL-17 itself is only partially required. Interestingly, in this model, the T-cell-independent psoriatic dermatitis that spontaneously develops in IL-1RN KO mice is not affected by IL-17A deficiency [58].

4.4. Type 1 Diabetes (T1D). In vitro activated OT1 $\mathrm{T}$ cells, transgenic $\mathrm{CD}^{+} \mathrm{T}$ cells that express the alpha and beta $\mathrm{T}$ cell-receptor specific for OVA peptide, induce rapid diabetes onset when transferred to mice expressing OVA peptide in pancreatic beta islet cells (RIP-OVA mice). It has been shown that in vitro treatment of OT1 cells with IL-23 promotes their differentiation into IL-17 producing $\mathrm{CD}^{+} \mathrm{T}$ cells (Tc17) and causes diabetes in an IL-17A- and IL-17F-dependent manner when adoptively transferred to RIP-OVA mice [59]. In a different setting, using the nonobese diabetes (NOD) animal model for Type 1 diabetes, disease is inhibited following treatment with anti-IL-17A antibodies during the effector phase of disease (at 10 weeks of age) rather than during the initiation of disease (mice less than 5 weeks of age) [60]. In contrast, it has been shown that IL-17A KO on the NOD background have comparable incidence of hyperglycemia to NOD mice with a WT allele for IL-17A. This could be due to expression of other IL-17 family members such IL-17F. Thus, while Th17 cells and IL-17A seem to play a role in T1D, the precise mechanism is not yet completely understood.

\section{Th17 Links Autoimmunity with Host Defense}

While it is clear that uncontrolled inflammation causes autoimmune pathologies, it remains to be seen what triggers the inflammation in these diseases. Several new studies suggest that exposure to pathogens initiates immune responses with an autoinflammatory outcome. Indeed, Th17 cells are induced by commensal bacteria in the small intestine lamina propria and are dependent on TGF $\beta$ but independent of IL-21, IL-23, and TLR signaling (MyD88 and Trif) [61]. However, the link between Th17 cells in the gut and autoimmune disease development at peripheral sites is not shown.

$\mathrm{K} / \mathrm{BxN}$ transgenic mice express autoreactive $\mathrm{T}$ cells specific for glucose 6 phosphate isomerase that promotes generation of high levels of auto-reactive antibodies, which subsequently induces ankle thickening. When these mice are housed in germ-free (GF) conditions, arthritis is greatly attenuated [62]. Indeed, disease reduction is correlated with a decreased number of $\mathrm{T}$ follicular helper cells and germinal center B cells in GF mice, suggesting that lack of microbes and their effect in adaptive immune response accounts for the reduced arthritis. Further, analysis of helper T cells from $\mathrm{K} / \mathrm{BxN}$ mice in GF conditions compared to animals housed in specific pathogen-free (SPF) facility shows a significant reduction in Th17 gene signatures (IL-17A, IL-21, IL-22, ROR $\gamma$ T, and CCR6). Neutralization of IL-17 with blocking antibodies at the time of arthritis onset (25 days old mice) completely abrogates disease, which is reflected in the low serum autoantibody titers. Moreover, following adoptive transfer, B cells from IL-17R-deficient mice failed to partake in the germinal center development. Overall, this study reveals a potential role of the IL17 pathway in regulating B cell function that a lack of Th17 cells and their downstream effects on germinal center B cells are critical factors in the disease reduction. A different study using IL-1R-antagonist(IL-1RN-) deficient mice that spontaneously develop T-cellmediated arthritis further supports a contribution of Th17 cells in autoimmune progression. Indeed, IL-1RN KO mice housed in germ-free conditions display reduced arthritis assayed by ankle thickness and histopathological analysis, while arthritis can be induced by infection with Lactobacillus bifidus in a TLR4-dependent manner [63]. Disease remission is associated with reduced Th17 cell number and decreased IL-17 secretion. In support of the above findings, mice in the SKG model (described above) do not develop arthritis if the animals are housed in microbially clean environment, despite the presence of arthritogenic autoimmune $\mathrm{T}$ cells, [64]. Treating mice with the yeast TLR2 ligand zymosan or glucose polymer $\beta$-1, 3-D-glucans ( $\beta$-glucans), the main constituents of zymosan, induces severe arthritis in SKG mice. Blockade of Dectin-1, a major $\beta$-glucan receptor, is able to prevent SKG arthritis triggered by $\beta$-glucans. Finally, polyinosinicpolycytidylic acid (poly[I:C]), a double-stranded RNA, also showed a mild arthritogenic effect in SKG mice. Together these studies strongly support the existence of a link between microbial stimuli and innate signaling to Th17 activation and autoimmunity (summarized in Figure 2).

\section{Potential Small Molecules to Target Th17 Cells}

Recent studies have identified small molecules that may be used as therapeutics to target $\mathrm{Th} 17^{+}$cells. The small molecule Halofuginone selectively inhibits mouse and human Th17 differentiation by activating the amino acid starvation response (AAR), a cytoprotective signaling pathway. Indeed, treatment with Halofuginone protects mice from Th17associated EAE [65]. Further, the cardiac glycoside Digoxin inhibits murine Th17 cell differentiation without affecting differentiation of other T-cell lineages and reduces the severity of EAE in mice [66]. In addition, leukemia inhibitory factor (LIF) produced by neural progenitor cells is able to ameliorate EAE by selectively inhibiting pathogenic Th17 cell differentiation $[67,68]$.

\section{Th17 Cells in Human Pathology and FDA-Approved Drugs}

In addition to preclinical results, clinical data show a correlation between enhanced IL-17 production and increased frequencies of Th17 cells in human disease (summarized in Table 2). High IL-17 levels are detected in the sera and biopsies of RA and SLE patients [18, 69-71]. Ex vivo, IL-17A promotes induction of proinflammatory cytokines IL- $1 \beta$ and IL-6 expression in synoviocytes from RA patients [72].

In MS patients, IL-17A mRNA is detected in cerebrospinal fluid mononuclear cells, and myelin reactive $\mathrm{Th} 17^{+}$ cells are also enriched [73]. Indeed, $\mathrm{Th}^{+} 7^{+}$cells from MS patients produce high amounts of IL-22 and IFN $\gamma$ and have 


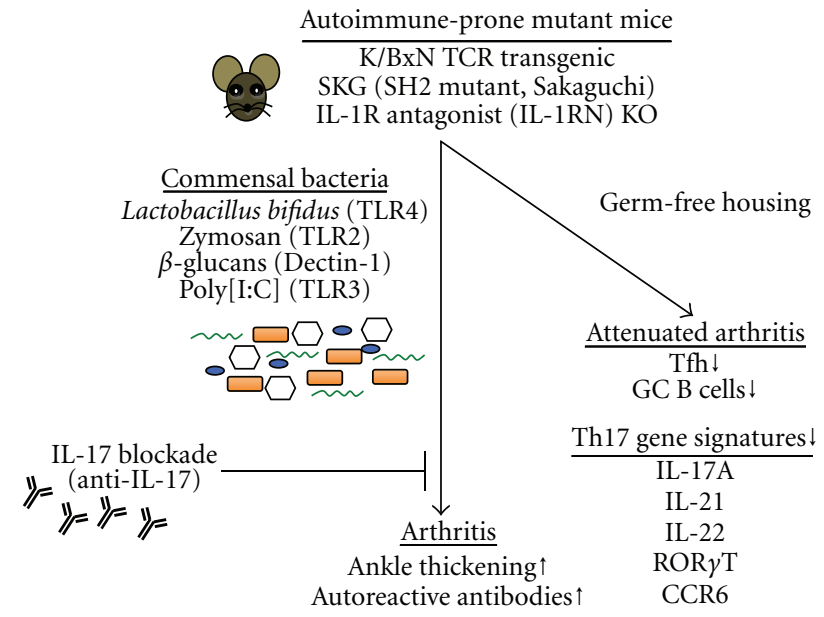

FIGURE 2: Linking Th17 cells and IL-17 to infection and autoimmunity.

TABLE 2: Clinical aspect of therapies targeting the IL-17 pathway.

\begin{tabular}{|c|c|c|c|c|c|c|}
\hline Disease & Sera & Biopsies & Cell type & $\begin{array}{l}\text { SNPs or } \\
\text { mutations }\end{array}$ & $\begin{array}{ll}\text { targeting } & \text { Th17 } \\
\end{array}$ & Reference \\
\hline Multiple sclerosis & & $\begin{array}{l}\text { IL-17A mRNA is } \\
\text { detected in } \\
\text { cerebrospinal fluid } \\
\text { mononuclear cells }\end{array}$ & $\begin{array}{l}\text { Myelin-reactive } \\
\text { Th1 } 17^{+} \text {cells are } \\
\text { enriched and express } \\
\text { high IL- } 22 \text { and IFN } \gamma\end{array}$ & & $\begin{array}{l}\text { Anti-p40 subunit of IL-12/23 } \\
\text { (ustekinumab) (no effect) }\end{array}$ & [73-75] \\
\hline $\begin{array}{l}\text { Rheumatoid } \\
\text { arthritis }\end{array}$ & IL-17 $\uparrow$ & IL-17 † & $\begin{array}{l}\text { Synoviocytes express } \\
\text { IL-1b and IL- } 6 \text { in } \\
\text { response to IL-17 }\end{array}$ & & $\begin{array}{l}\text { Anti-IL-6R (Tocilizumab); IL- } \\
1 \text { receptor antagonist (anakin- } \\
\text { ra); anti-IL17 (LY2439821, oth- } \\
\text { ers) }\end{array}$ & {$[69,72,76-78]$} \\
\hline $\begin{array}{l}\text { Systemic lupus } \\
\text { erythematosus }\end{array}$ & IL-17 $\uparrow$ & IL-17 $\uparrow$ & & & & {$[18,70,71]$} \\
\hline Psoriasis & & $\begin{array}{l}\text { IL-17A, IL-22, and } \\
\text { IL-23 }\end{array}$ & $\begin{array}{l}\mathrm{CD} 88^{+} \mathrm{T} \text { cells secreting } \\
\text { IL-17 and IL-22 } \\
\text { (Tc17 and Tc22, } \\
\text { respectively) }\end{array}$ & $\begin{array}{l}\text { IL-23 } \\
\text { pathway }\end{array}$ & $\begin{array}{l}\text { Anti-p40 subunit of IL-12 and } \\
\text { IL-23 (ustekinumab) }\end{array}$ & [79-82] \\
\hline $\begin{array}{l}\text { Inflammatory } \\
\text { Bowel disease }\end{array}$ & & & & $\begin{array}{l}\text { IL-23 } \\
\text { pathway }\end{array}$ & & [83] \\
\hline Crohn's disease & & $\begin{array}{l}\mathrm{IL}-17^{+}\left(\mathrm{ROR} \gamma \mathrm{T}^{+}\right. \\
\mathrm{IL}-23 \mathrm{R}^{+} \text {and } \\
\left.\text { CCR6 }{ }^{+} \text {cells }\right) \uparrow\end{array}$ & $\begin{array}{l}\text { Th17 }\left(\mathrm{CD} 161^{+} \mathrm{CD} 4^{+}\right. \\
\text {T cells })\end{array}$ & & $\begin{array}{l}\text { Anti-IL-6R (Tocilizumab); anti- } \\
\text { p40 subunit of IL-12/23 (us- } \\
\text { tekinumab) }\end{array}$ & {$[76,84-86]$} \\
\hline
\end{tabular}

the ability to cross the blood brain barrier, which likely contributes to the mechanism of disease pathology [74].

Moreover, $\mathrm{CD}^{+} \mathrm{T}$ cells secreting IL-17 and IL-22 (Tc17 and Tc22, resp.) are thought to mediate pathogenic inflammation in psoriasis. In fact, IL-17A, IL-22, and IL-23 are elevated in psoriatic skin, and IL-17A together with TNF $\alpha$ induces the expression of genes involved in psoriasis in human keratinocytes [79, 80]. Furthermore, single-nucleotide polymorphisms (SNPs) in genes involved in IL-23 signaling (IL23A, IL23R, and IL12B) are also associated with psoriasis [87]. In addition, uncommon $I l 23 r$ variants inversely correlated with susceptibility to IBD have also been found in IBD patients [83].

A significantly higher number of $\mathrm{IL}-17^{+}$cells is detected in disease-affected gut areas compared to healthy areas of the same subjects with Crohn's disease (CD) [84]. These cells express ROR $\gamma \mathrm{T}$ and are IL-23R ${ }^{+}$and $\mathrm{CCR} 6^{+}$. Functionally, they are capable of providing B-cell help, display low cytotoxic ability, and are resistant to Foxp $3^{+}$Treg suppression. Together this data demonstrates that $\mathrm{Th} 17^{+}$cells are indeed detected in the inflamed tissues of CD patients. An additional marker for Th17 cells in humans could be the C-type lectinlike receptor CD161, which has recently been described to promote $\mathrm{T}$-cell expansion and is expressed on a discrete subset of human $\mathrm{CD} 4^{+} \mathrm{T}$ cells in circulation and in the gut of CD patients [85]. CD $161^{+} \mathrm{CD} 4^{+} \mathrm{T}$ cells display an activated Th17 phenotype as indicated by increased expression of IL23R and production of IL-17 and IL-22.

Biologic therapeutics blocking pathways implicated in Th17 development or blocking IL-17 itself are currently being developed. An anti-IL6 receptor antibody (tocilizumab, Hoffmann-La Roche and Chugai) is currently used to treat 
RA and Crohn's disease [76], while ongoing clinical trials are being developed by diverse biotechnology and pharmaceutical companies. While IL-6 signaling is important for Th17 development, it remains unclear if the mechanism of action of this blocking antibody is through prevention of Th17 development.

IL-1 receptor antagonist (anakinra) has been successfully used in treatment of RA [77] and the mechanism of action could be mediated by reduction of $\mathrm{Th}^{+} 7^{+}$cells, although IL-1R signaling affects several immune pathways. Further studies are required to determine if Th17 cells are affected by either of these therapies.

In addition, blockade of IL-23 signaling using a monoclonal antibody (ustekinumab) against the p40 subunit of IL-12 and IL-23 has been shown to be effective in Crohn's disease, psoriasis and psoriatic arthritis with results similar to those seen when blocking IL-6 or TNF $\alpha[81,82,86]$. This antibody has no substantial effect as a therapy for MS despite several preclinical studies using the EAE model in mice [75], providing additional evidence that findings generated in animal studies need to be verified using human samples in order to be validated.

A humanized antibody blocking IL-17A is being developed to treat RA (LY2439821, Eli Lilly)[78], and phase I clinical trials showed positive results. Another humanized anti-IL-17 antibody is being developed for the treatment of RA, psoriasis, and uveitis [88]. Patients treated with this antibody show a similar reduction in symptoms to those treated with the anti-TNF blocking antibody infliximab (Remicade), validating IL-17A as a strong mediator in inflammatory autoimmune diseases.

Paradoxically, recent studies suggest that IL-17 could have a protective role in atherosclerosis [89] and that Th17 cells seem to regulate autoimmune manifestations associated with AIRE deficiency. Similarly, chronic mucocutaneous candidiasis is associated with elevated Th17 cytokines in APECED patients, further linking the Th17 pathway with autoimmunity [90].

\section{Adult Onset Still's Disorder and Th17}

Adult onset Still's disorder (AOSD) is an inflammatory autoimmune disorder characterized by high spiking fever, evanescent rash, arthritis, hepatosplenomegaly, variable multisystemic involvement, and laboratory abnormalities that include neutrophilic leukocytosis and hyperferritinaemia [91, 92]. It has been shown that proinflammatory cytokines IL$1 \beta$, IL-6, and IL-18 are elevated in AOSD patients [93-96]. As described above, these cytokines are associated with inducing and maintaining Th17 function. To test if Th17 cells were elevated in AOSD patients, Chen et al. performed intracellular cytokine staining and flow cytometry to assay for Th17 cells in peripheral blood. In this study, it was found that Th17 cells are significantly elevated in patients with active untreated AOSD compared to healthy volunteers. Further, the cells decrease nearly 10 -fold during clinical remission and serum levels of ferritin decrease as well [97]. The frequencies of Th17 cells are similarly elevated in patients with active SLE, which was previously shown to have increased
Th17 cells [98]. Furthermore, the frequency of Th17 cells was positively correlated with levels of Th17-related cytokines (IL-17, IL-1 $\beta$, IL-6, IL-18, IL-21, and IL-23) and with disease activity score based on serum ferritin levels. Interestingly, the frequency of Th17 cells was reduced in patients after corticosteroid (CSs) and nonsteroidal anti-inflammatory drug (NSAIDs) therapy that were in remission phase. This new study shows a correlation between Th17 cells and disease progression; however, it remains unknown if Th17 cells are part of the pathogenic mechanism in development of AOSD.

An additional autoimmune disease in which the Th17 pathway has been implicated is childhood Henoch-Schönlein purpura (HSP), a common childhood systemic vasculitis in which increased frequency of peripheral Th17 cells and serum IL-17 levels occur [99]. There is also evidence from mice suggesting that Th17 cells contribute to autoimmune myocarditis development [100-102].

\section{Conclusion}

Substantial progress in understanding Th17 development and the effects of IL-17 signaling in immune responses has revealed high potential for targeting this pathway in immune pathologies. The ability to target or redirect T-cell lineage development can greatly ameliorate autoinflammation in preclinical models. However, a better understanding of the cytokines involved in the induction of Th17 differentiation and the balance between Th17 versus Treg and Th1 development during infection or autoimmunity requires further investigation. Finally, linking relevant animal disease models with clinical studies could improve our understanding of how these cells contribute to disease pathogenesis.

\section{References}

[1] L. E. Harrington, R. D. Hatton, P. R. Mangan et al., "Interleukin 17-producing CD4+ effector T cells develop via a lineage distinct from the $\mathrm{T}$ helper type 1 and 2 lineages," Nature Immunology, vol. 6, no. 11, pp. 1123-1132, 2005.

[2] C. L. Langrish, Y. Chen, W. M. Blumenschein et al., "IL-23 drives a pathogenic $\mathrm{T}$ cell population that induces autoimmune inflammation," Journal of Experimental Medicine, vol. 201, no. 2, pp. 233-240, 2005.

[3] H. Park, Z. Li, X. O. Yang et al., "A distinct lineage of CD4 T cells regulates tissue inflammation by producing interleukin 17," Nature Immunology, vol. 6, no. 11, pp. 1133-1141, 2005.

[4] Y. Chung, S. H. Chang, G. J. Martinez et al., "Critical regulation of early Th17 cell differentiation by interleukin-1 signaling," Immunity, vol. 30, no. 4, pp. 576-587, 2009.

[5] K. Hirahara, K. Ghoreschi, A. Laurence, X. P. Yang, Y. Kanno, and J. J. O'Shea, "Signal transduction pathways and transcriptional regulation in Th17 cell differentiation," Cytokine and Growth Factor Reviews, vol. 21, no. 6, pp. 425-434, 2010.

[6] T. Korn, E. Bettelli, M. Oukka, and V. K. Kuchroo, "IL-17 and Th17 cells," Annual Review of Immunology, vol. 27, pp. 485517, 2009.

[7] C. E. Sutton, S. J. Lalor, C. M. Sweeney, C. F. Brereton, E. C. Lavelle, and K. H. G. Mills, "Interleukin-1 and IL-23 induce innate IL-17 production from $\gamma \delta$ T cells, amplifying Th17 responses and autoimmunity," Immunity, vol. 31, no. 2, pp. 331-341, 2009. 
[8] L. Yang, D. E. Anderson, C. Baecher-Allan et al., "IL-21 and TGF- $\beta$ are required for differentiation of human $\mathrm{T}(\mathrm{H}) 17$ cells," Nature, vol. 454, no. 7202, pp. 350-352, 2008.

[9] M. Veldhoen, R. J. Hocking, C. J. Atkins, R. M. Locksley, and B. Stockinger, "TGF $\beta$ in the context of an inflammatory cytokine milieu supports de novo differentiation of IL-17-producing T cells," Immunity, vol. 24, no. 2, pp. 179-189, 2006.

[10] M. Veldhoen, R. J. Hocking, R. A. Flavell, and B. Stockinger, "Signals mediated by transforming growth factor- $\beta$ initiate autoimmune encephalomyelitis, but chronic inflammation is needed to sustain disease," Nature Immunology, vol. 7, no. 11, pp. 1151-1156, 2006.

[11] J. Das, G. Ren, L. Zhang et al., "Transforming growth factor $\beta$ is dispensable for the molecular orchestration of Th17 cell differentiation," Journal of Experimental Medicine, vol. 206, no. 11, pp. 2407-2416, 2009.

[12] K. Ghoreschi, A. Laurence, X. P. Yang et al., "Generation of pathogenic $\mathrm{T}(\mathrm{H}) 17$ cells in the absence of TGF- $\beta 2$ signalling," Nature, vol. 467, no. 7318, pp. 967-971, 2010.

[13] I. I. Ivanov, B. S. McKenzie, L. Zhou et al., "The orphan nuclear receptor ROR $\gamma \mathrm{t}$ directs the differentiation program of proinflammatory IL-17+ T helper cells," Cell, vol. 126, no. 6, pp. 1121-1133, 2006.

[14] T. Korn, E. Bettelli, W. Gao et al., "IL-21 initiates an alternative pathway to induce proinflammatory $\mathrm{T}(\mathrm{H}) 17$ cells," Nature, vol. 448, no. 7152, pp. 484-487, 2007.

[15] R. Nurieva, X. O. Yang, G. Martinez et al., "Essential autocrine regulation by IL- 21 in the generation of inflammatory T cells," Nature, vol. 448, no. 7152, pp. 480-483, 2007.

[16] L. Guo, G. Wei, J. Zhu et al., "IL-1 family members and STAT activators induce cytokine production by Th2, Th17, and Th1 cells," Proceedings of the National Academy of Sciences of the United States of America, vol. 106, no. 32, pp. $13463-$ 13468, 2009.

[17] A. N. Mathur, H. C. Chang, D. G. Zisoulis et al., "Stat3 and stat4 direct development of IL-17-secreting Th cells," Journal of Immunology, vol. 178, no. 8, pp. 4901-4907, 2007.

[18] C. K. Wong, L. C. W. Lit, L. S. Tam, E. K. M. Li, P. T. Y. Wong, and C. W. K. Lam, "Hyperproduction of IL-23 and IL-17 in patients with systemic lupus erythematosus: implications for Th17-mediated inflammation in auto-immunity," Clinical Immunology, vol. 127, no. 3, pp. 385-393, 2008.

[19] C. A. Dinarello, "IL-18: AtH1-inducing, proinflammatory cytokine and new member of the IL-1 family," Journal of Allergy and Clinical Immunology, vol. 103, no. 1, pp. 11-24, 1999.

[20] L. L. Reznikov, S. H. Kim, J. Y. Westcott et al., "IL-18 binding protein increases spontaneous and IL-1-induced prostaglandin production via inhibition of IFN- $\gamma$," Proceedings of the National Academy of Sciences of the United States of America, vol. 97, no. 5, pp. 2174-2179, 2000.

[21] C. T. Weaver, R. D. Hatton, P. R. Mangan, and L. E. Harrington, "IL-17 family cytokines and the expanding diversity of effector T cell lineages," Annual Review of Immunology, vol. 25, pp. 821-852, 2007.

[22] S. L. Gaffen, "Structure and signalling in the IL-17 receptor family," Nature Reviews Immunology, vol. 9, no. 8, pp. 556$567,2009$.

[23] H. Ishigame, S. Kakuta, T. Nagai et al., "Differential roles of interleukin-17A and -17F in host defense against mucoepithelial bacterial infection and allergic responses," Immunity, vol. 30, no. 1, pp. 108-119, 2009.

[24] R. E. Kuestner, D. W. Taft, A. Haran et al., "Identification of the IL-17 receptor related molecule IL-17RC as the receptor for IL-17F," Journal of Immunology, vol. 179, no. 8, pp. 54625473, 2007.

[25] A. W. Ho and S. L. Gaffen, "IL-17RC: a partner in IL-17 signaling and beyond," Seminars in Immunopathology, vol. 32, no. 1, pp. 33-42, 2010.

[26] J. K. Kolls and A. Lindén, "Interleukin-17 family members and inflammation," Immunity, vol. 21, no. 4, pp. 467-476, 2004.

[27] P. Schwarzenberger, W. Huang, Y. Peng et al., "Requirement of endogenous stem cell factor and granulocyte-colonystimulating factor for IL-17-mediated granulopoiesis," Journal of Immunology, vol. 164, no. 9, pp. 4783-4789, 2000.

[28] P. Schwarzenberger, V. La Russa, A. Miller et al., "IL17 stimulates granulopoiesis in mice: use of an alternate, novel gene therapy-derived method for in vivo evaluation of cytokines," Journal of Immunology, vol. 161, no. 11, pp. 63836389, 1998.

[29] M. A. Stark, Y. Huo, T. L. Burcin, M. A. Morris, T. S. Olson, and K. Ley, "Phagocytosis of apoptotic neutrophils regulates granulopoiesis via IL-23 and IL-17," Immunity, vol. 22, no. 3, pp. 285-294, 2005.

[30] L. Codarri, G. Gyülvészii, V. Tosevski et al., "ROR $\gamma 3$ t drives production of the cytokine GM-CSF in helper $\mathrm{T}$ cells, which is essential for the effector phase of autoimmune neuroinflammation," Nature Immunology, vol. 12, no. 6, pp. 560-567, 2011.

[31] M. El-Behi, B. Ciric, H. Dai et al., "The encephalitogenicity of $\mathrm{T}(\mathrm{H}) 17$ cells is dependent on IL-1- and IL-23-induced production of the cytokine GM-CSF," Nature Immunology, vol. 12, no. 6, pp. 568-575, 2011.

[32] W. Hou, H. S. Kang, and B. S. Kim, "Th17 cells enhance viral persistence and inhibit $\mathrm{T}$ cell cytotoxicity in a model of chronic virus infection," Journal of Experimental Medicine, vol. 206, no. 2, pp. 313-328, 2009.

[33] J. S. Stumhofer, A. Laurence, E. H. Wilson et al., "Interleukin 27 negatively regulates the development of interleukin 17producing $\mathrm{T}$ helper cells during chronic inflammation of the central nervous system," Nature Immunology, vol. 7, no. 9, pp. 937-945, 2006.

[34] C. F. Anderson, J. S. Stumhofer, C. A. Hunter, and D. Sacks, "IL-27 regulates IL-10 and IL-17 from CD4+ cells in nonhealing Leishmania major infection," Journal of Immunology, vol. 183, no. 7, pp. 4619-4627, 2009.

[35] C. A. Murphy, C. L. Langrish, Y. Chen et al., "Divergent pro- and antiinflammatory roles for IL-23 and IL-12 in joint autoimmune inflammation," Journal of Experimental Medicine, vol. 198, no. 12, pp. 1951-1957, 2003.

[36] S. Nakae, A. Nambu, K. Sudo, and Y. Iwakura, "Suppression of immune induction of collagen-induced arthritis in IL-17deficient mice," Journal of Immunology, vol. 171, no. 11, pp. 6173-6177, 2003.

[37] H. Ogura, M. Murakami, Y. Okuyama et al., "Interleukin17 promotes autoimmunity by triggering a positive-feedback loop via interleukin-6 induction," Immunity, vol. 29 , no. 4 , pp. 628-636, 2008.

[38] N. Sakaguchi, T. Takahashi, H. Hata et al., "Altered thymic T-cell selection due to a mutation of the ZAP-70 gene causes autoimmune arthritis in mice," Nature, vol. 426, no. 6965, pp. 454-460, 2003.

[39] K. Hirota, M. Hashimoto, H. Yoshitomi et al., "T cell selfreactivity forms a cytokine milieu for spontaneous development of IL-17+ Th cells that cause autoimmune arthritis," Journal of Experimental Medicine, vol. 204, no. 1, pp. 41-47, 2007. 
[40] Y. Iwakura, S. Saijo, Y. Kioka et al., "Autoimmunity induction by human $\mathrm{T}$ cell leukemia virus type 1 in transgenic mice that develop chronic inflammatory arthropathy resembling rheumatoid arthritis in humans," Journal of Immunology, vol. 155, no. 3, pp. 1588-1598, 1995.

[41] Y. Iwakura, S. Nakae, S. Saijo, and H. Ishigame, "The roles of IL-17A in inflammatory immune responses and host defense against pathogens," Immunological Reviews, vol. 226, no. 1, pp. 57-79, 2008.

[42] W. O'Connor Jr., M. Kamanaka, C. J. Booth et al., "A protective function for interleukin 17A in T cell-mediated intestinal inflammation," Nature Immunology, vol. 10, no. 6, pp. 603-609, 2009.

[43] M. Leppkes, C. Becker, I. I. Ivanov et al., "ROR $\gamma$-expressing Th17 cells induce murine chronic intestinal inflammation via redundant effects of IL-17A and IL-17F," Gastroenterology, vol. 136, no. 1, pp. 257-267, 2009.

[44] A. Ogawa, A. Andoh, Y. Araki, T. Bamba, and Y. Fujiyama, "Neutralization of interleukin-17 aggravates dextran sulfate sodium-induced colitis in mice," Clinical Immunology, vol. 110, no. 1, pp. 55-62, 2004.

[45] X. O. Yang, H. C. Seon, H. Park et al., "Regulation of inflammatory responses by IL-17F," Journal of Experimental Medicine, vol. 205, no. 5, pp. 1063-1075, 2008.

[46] R. Ito, M. Kita, M. Shin-Ya et al., "Involvement of IL-17A in the pathogenesis of DSS-induced colitis in mice," Biochemical and Biophysical Research Communications, vol. 377, no. 1, pp. 12-16, 2008.

[47] L. A. Zenewicz, G. D. Yancopoulos, D. M. Valenzuela, A. J. Murphy, S. Stevens, and R. A. Flavell, "Innate and adaptive interleukin-22 protects mice from inflammatory bowel disease," Immunity, vol. 29, no. 6, pp. 947-957, 2008.

[48] S. Huber, N. Gagliani, E. Esplugues et al., "Th17 cells express interleukin-10 receptor and are controlled by Foxp3and Foxp3+ regulatory CD4+ T cells in an interleukin-10dependent manner," Immunity, vol. 34, no. 4, pp. 554-565, 2011.

[49] A. Chaudhry, R. Samstein, P. Treuting et al., "Interleukin-10 signaling in regulatory $\mathrm{T}$ cells is required for suppression of Th17 cell-mediated inflammation," Immunity, vol. 34, no. 4, pp. 566-578, 2011.

[50] Y. Chen, C. Haines, I. Gutcher et al., "Foxp3(+) regulatory T cells promote $\mathrm{T}$ helper 17 cell development in vivo through regulation of interleukin-2," Immunity, vol. 34, no. 3, pp. 409-421, 2011.

[51] P. Pandiyan, H. R. Conti, L. Zheng et al., "CD4(+)CD25(+) Foxp3(+) regulatory T cells promote Th17 cells in vitro and enhance host resistance in mouse Candida albicans Th17 cell infection model," Immunity, vol. 34, no. 3, pp. 422-434, 2011.

[52] M. A. Lowes, T. Kikuchi, J. Fuentes-Duculan et al., "Psoriasis vulgaris lesions contain discrete populations of Th1 and Th17 T cells," Journal of Investigative Dermatology, vol. 128, no. 5, pp. 1207-1211, 2008.

[53] L. van der Fits, S. Mourits, J. S. A. Voerman et al., "Imiquimod-induced psoriasis-like skin inflammation in mice is mediated via the IL-23/IL-17 axis," Journal of Immunology, vol. 182, no. 9, pp. 5836-5845, 2009.

[54] M. N. Hedrick, A. S. Lonsdorf, A. K. Shirakawa et al., "CCR6 is required for IL-23-induced psoriasis-like inflammation in mice," Journal of Clinical Investigation, vol. 119, no. 8, pp. 2317-2329, 2009.

[55] J. Lindroos, L. Svensson, H. Norsgaard et al., "IL-23-mediated epidermal hyperplasia is dependent on IL-6," Journal of Investigative Dermatology, vol. 131, no. 5, pp. 1110-1118, 2011.
[56] H. L. Rizzo, S. Kagami, K. G. Phillips, S. E. Kurtz, S. L. Jacques, and A. Blauvelt, "IL-23-mediated psoriasis-like epidermal hyperplasia is dependent on IL-17A," Journal of Immunology, vol. 186, no. 3, pp. 1495-1502, 2011.

[57] K. Nakajima, T. Kanda, M. Takaishi et al., "Distinct roles of IL-23 and IL-17 in the development of psoriasis-like lesions in a mouse model," Journal of Immunology, vol. 186, no. 7, pp. 4481-4489, 2011.

[58] A. Nakajima, T. Matsuki, M. Komine et al., "TNF, but not IL-6 and IL-17, is crucial for the development of T cellindependent psoriasis-like dermatitis in Il1rn-/- mice," Journal of Immunology, vol. 185, no. 3, pp. 1887-1893, 2010.

[59] B. Ciric, M. El-behi, R. Cabrera, G. X. Zhang, and A. Rostami, "IL-23 drives pathogenic IL-17-producing CD8+ T cells," Journal of Immunology, vol. 182, no. 9, pp. 5296-5305, 2009.

[60] J. A. Emamaullee, J. Davis, S. Merani et al., "Inhibition of Th17 cells regulates autoimmune diabetes in NOD mice," Diabetes, vol. 58, no. 6, pp. 1302-1311, 2009.

[61] I. I. Ivanov, R. D. L. Frutos, N. Manel et al., "Specific microbiota direct the differentiation of IL-17-producing T-helper cells in the mucosa of the small intestine," Cell Host and Microbe, vol. 4, no. 4, pp. 337-349, 2008.

[62] H. J. Wu, I. I. Ivanov, J. Darce et al., "Gut-residing segmented filamentous bacteria drive autoimmune arthritis via T helper 17 cells," Immunity, vol. 32, no. 6, pp. 815-827, 2010.

[63] S. Abdollahi-Roodsaz, L. A. B. Joosten, M. I. Koenders et al., "Stimulation of TLR2 and TLR4 differentially skews the balance of T cells in a mouse model of arthritis," Journal of Clinical Investigation, vol. 118, no. 1, pp. 205-216, 2008.

[64] H. Yoshitomi, N. Sakaguchi, K. Kobayashi et al., "A role for fungal $\beta$-glucans and their receptor dectin- 1 in the induction of autoimmune arthritis in genetically susceptible mice," Journal of Experimental Medicine, vol. 201, no. 6, pp. 949960, 2005.

[65] M. S. Sundrud, S. B. Koralov, M. Feuerer et al., "Halofuginone inhibits th 17 cell differentiation by activating the amino acid starvation response," Science, vol. 324, no. 5932, pp. 1334-1338, 2009.

[66] J. R. Huh, M. W.L. Leung, P. Huang et al., "Digoxin and its derivatives suppress TH17 cell differentiation by antagonizing ROR 33 t activity," Nature, vol. 472, no. 7344, pp. 486-490, 2011.

[67] A. Awasthi and V. Kuchroo, "Value added: neural progenitor cells suppress inflammation and autoimmunity," Immunity, vol. 35, no. 2, pp. 156-157, 2011.

[68] W. Cao, Y. Yang, Z. Wang et al., "Leukemia inhibitory factor inhibits $T$ helper 17 cell differentiation and confers treatment effects of neural progenitor cell therapy in autoimmune disease," Immunity, vol. 35, no. 2, pp. 273-284, 2011.

[69] S. Agarwal, R. Misra, and A. Aggarwal, "Interleukin 17 levels are increased in juvenile idiopathic arthritis synovial fluid and induce synovial fibroblasts to produce proinflammatory cytokines and matrix metalloproteinases," Journal of Rheumatology, vol. 35, no. 3, pp. 515-519, 2008.

[70] F. C. Liu, D. M. Chang, J. H. Lai et al., "Autoimmune hepatitis with raised alpha-fetoprotein level as the presenting symptoms of systemic lupus erythematosus: a case report," Rheumatology International, vol. 27, no. 5, pp. 489-491, 2007.

[71] C. K. Wong, C. Y. Ho, E. K. Li, and C. W. K. Lam, "Elevation of proinflammatory cytokine (IL-18, IL-17, IL-12) and Th2 cytokine (IL-4) concentrations in patients with systemic lupus erythematosus," Lupus, vol. 9, no. 8, pp. 589-593, 2000.

[72] M. Chabaud, F. Fossiez, J. L. Taupin, and P. Miossec, "Enhancing effect of IL-17 on IL-1-induced IL-6 and leukemia 
inhibitory factor production by rheumatoid arthritis synoviocytes and its regulation by Th2 cytokines," Journal of Immunology, vol. 161, no. 1, pp. 409-414, 1998.

[73] K. Venken, N. Hellings, K. Hensen, J. L. Rummens, and P. Stinissen, "Memory CD4+CD127high T cells from patients with multiple sclerosis produce IL-17 in response to myelin antigens," Journal of Neuroimmunology, vol. 226, no. 1-2, pp. 185-191, 2010.

[74] H. Kebir, I. Ifergan, J. I. Alvarez et al., "Preferential recruitment of interferon- $\gamma$-expressing TH17 cells in multiple sclerosis," Annals of Neurology, vol. 66, no. 3, pp. 390-402, 2009.

[75] B. M. Segal, C. S. Constantinescu, A. Raychaudhuri, L. Kim, R. Fidelus-Gort, and L. H. Kasper, "Repeated subcutaneous injections of IL12/23 p40 neutralising antibody, ustekinumab, in patients with relapsing-remitting multiple sclerosis: a phase II, double-blind, placebo-controlled, randomised, dose-ranging study," The Lancet Neurology, vol. 7, no. 9, pp. 796-804, 2008.

[76] A. M. Patel and L. W. Moreland, "Interleukin-6 inhibition for treatment of rheumatoid arthritis: a review of tocilizumab therapy," Drug Design, Development and Therapy, vol. 4, pp. 263-278, 2010.

[77] M. Geyer and U. Müller-Ladner, "Actual status of antiinterleukin-1 therapies in rheumatic diseases," Current Opinion in Rheumatology, vol. 22, no. 3, pp. 246-251, 2010.

[78] M. C. Genovese, F. van den Bosch, S. A. Roberson et al., "LY2439821, a humanized anti-interleukin-17 monoclonal antibody, in the treatment of patients with rheumatoid arthritis: a phase I randomized, double-blind, placebo-controlled, proof-of-concept study," Arthritis and Rheumatism, vol. 62, no. 4, pp. 929-939, 2010.

[79] P. C. M. Res, G. Piskin, O. J. de Boer et al., "Overrepresentation of IL-17A and IL-22 producing CD8 T cells in lesional skin suggests their involvement in the pathogenesis of psoriasis," PLoS ONE, vol. 5, no. 11, Article ID e14108, 2010.

[80] N. J. Wilson, K. Boniface, J. R. Chan et al., "Development, cytokine profile and function of human interleukin 17-producing helper T cells," Nature Immunology, vol. 8, no. 9, pp. 950957, 2007.

[81] A. Gottlieb, A. Menter, A. Mendelsohn et al., "Ustekinumab, a human interleukin 12/23 monoclonal antibody, for psoriatic arthritis: randomised, double-blind, placebo-controlled, crossover trial," The Lancet, vol. 373, no. 9664, pp. 633-640, 2009.

[82] C. E.M. Griffiths, "Comparing biological therapies in psoriasis: implications for clinical practice," Journal of the European Academy of Dermatology and Venereology, vol. 24, supplement 6, pp. 10-14, 2010.

[83] R. H. Duerr, K. D. Taylor, S. R. Brant et al., "A genomewide association study identifies IL23R as an inflammatory bowel disease gene," Science, vol. 314, no. 5804, pp. 1461$1463,2006$.

[84] F. Annunziato, L. Cosmi, V. Santarlasci et al., "Phenotypic and functional features of human Th17 cells," Journal of Experimental Medicine, vol. 204, no. 8, pp. 1849-1861, 2007.

[85] M. A. Kleinschek, K. Boniface, S. Sadekova et al., "Circulating and gut-resident human Th17 cells express CD161 and promote intestinal inflammation," Journal of Experimental Medicine, vol. 206, no. 3, pp. 525-534, 2009.

[86] C. L. Leonardi, A. B. Kimball, K. A. Papp et al., "Efficacy and safety of ustekinumab, a human interleukin-12/23 monoclonal antibody, in patients with psoriasis: 76 -week results from a randomised, double-blind, placebo-controlled trial
(PHOENIX 1)," The Lancet, vol. 371, no. 9625, pp. 16651674,2008

[87] R. P. Nair, K. C. Duffin, C. Helms et al., "Genome-wide scan reveals association of psoriasis with IL-23 and NF- $\kappa$ B pathways," Nature Genetics, vol. 41, no. 2, pp. 199-204, 2009.

[88] A. M. Huber, I. Gaboury, D. A. Cabral et al., "Prevalent vertebral fractures among children initiating glucocorticoid therapy for the treatment of rheumatic disorders," Arthritis Care and Research, vol. 62, no. 4, pp. 516-526, 2010.

[89] S. Taleb, M. Romain, B. Ramkhelawon et al., "Loss of SOCS3 expression in $\mathrm{T}$ cells reveals a regulatory role for interleukin17 in atherosclerosis," Journal of Experimental Medicine, vol. 206, no. 10, pp. 2067-2077, 2009.

[90] K. Kisand, A. S. Bøe Wolff, K. T. Podkrajšek et al., "Chronic mucocutaneous candidiasis in APECED or thymoma patients correlates with autoimmunity to Th17-associated cytokines," Journal of Experimental Medicine, vol. 207, no. 2, pp. 299-308, 2010.

[91] E. G. Bywaters, "Still's disease in the adult," Annals of the Rheumatic Diseases, vol. 30, no. 2, pp. 121-133, 1971.

[92] A. Ohta, M. Yamaguchi, H. Kaneoka, T. Nagayoshi, and M. Hiida, "Adult Still's disease: review of 228 cases from the literature," Journal of Rheumatology, vol. 14, no. 6, pp. 11391146, 1988.

[93] D. Y. Chen, J. L. Lan, F. J. Lin, and T. Y. Hsieh, "Proinflammatory cytokine profiles in sera and pathological tissues of patients with active untreated adult onset still's disease," Journal of Rheumatology, vol. 31, no. 11, pp. 2189-2198, 2004.

[94] D. Y. Chen, J. L. Lan, F. J. Lin, T. Y. Hsieh, and M. C. Wen, "Predominance of Th1 cytokine in peripheral blood and pathological tissues of patients with active untreated adult onset Still's disease," Annals of the Rheumatic Diseases, vol. 63, no. 10, pp. 1300-1306, 2004.

[95] J. H. Choi, C. H. Suh, Y. M. Lee et al., "Serum cytokine profiles in patients with adult onset Still's disease," Journal of Rheumatology, vol. 30, no. 11, pp. 2422-2427, 2003.

[96] M. Kawashima, M. Yamamura, M. Taniai et al., "Levels of interleukin-18 and its binding inhibitors in the blood circulation of patients with adult-onset Still's disease," Arthritis and Rheumatism, vol. 44, no. 3, pp. 550-560, 2001.

[97] D. Y. Chen, Y. M. Chen, J. L. Lan, C. C. Lin, H. H. Chen, and C. W. Hsieh, "Potential role of th17 cells in the pathogenesis of adult-onset Still's disease," Rheumatology, vol. 49, no. 12, Article ID keq284, pp. 2305-2312, 2010.

[98] J. Yang, Y. Chu, X. Yang et al., "Th17 and natural treg cell population dynamics in systemic lupus erythematosus," Arthritis and Rheumatism, vol. 60, no. 5, pp. 1472-1483, 2009.

[99] H. Y. Jen, Y. H. Chuang, S. C. Lin, B. L. Chiang, and Y. H. Yang, "Increased serum interleukin-17 and peripheral Th17 cells in children with acute Henoch-Schönlein purpura," Pediatric Allergy and Immunology, vol. 22, no. 8, pp. 862-868, 2011.

[100] H. Chang, H. Hanawa, T. Yoshida et al., "Alteration of IL17 related protein expressions in experimental autoimmune myocarditis and inhibition of IL-17 by IL-10-Ig fusion gene transfer," Circulation Journal, vol. 72, no. 5, pp. 813-819, 2008.

[101] Z. Su, C. Sun, C. Zhou et al., "HMGB 1 blockade attenuates experimental autoimmune myocarditis possibly by suppressing Th17-cell expansion," European Journal of Immunology, vol. 41, no. 12, pp. 3586-3595, 2011.

[102] A. Valaperti, R. R. Marty, G. Kania et al., "CD11b+ monocytes abrogate Th17 CD4+ T cell-mediated experimental autoimmune myocarditis," Journal of Immunology, vol. 180, no. 4, pp. 2686-2695, 2008. 


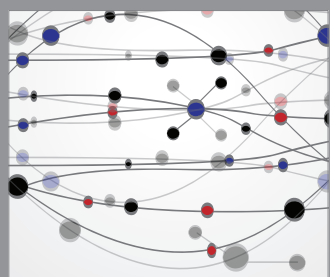

The Scientific World Journal
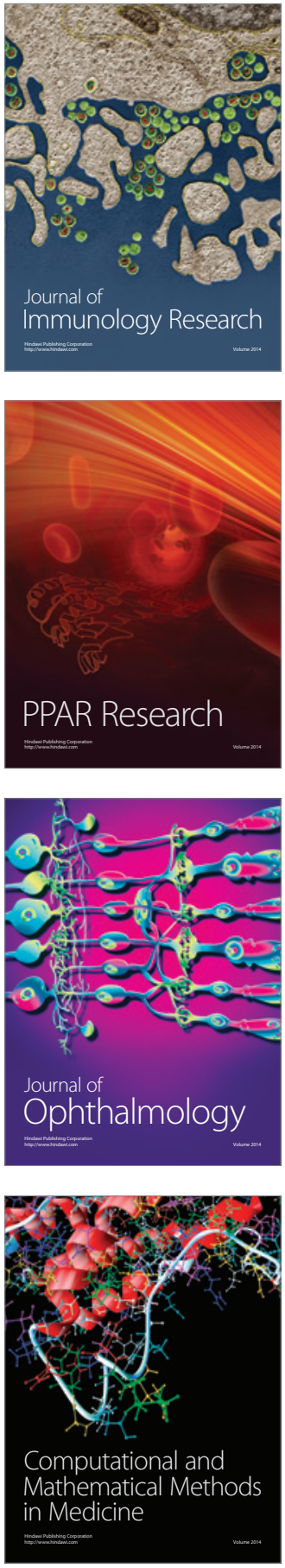

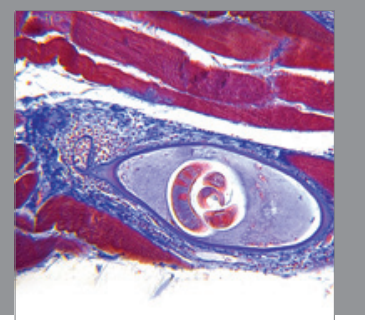

Gastroenterology

Research and Practice
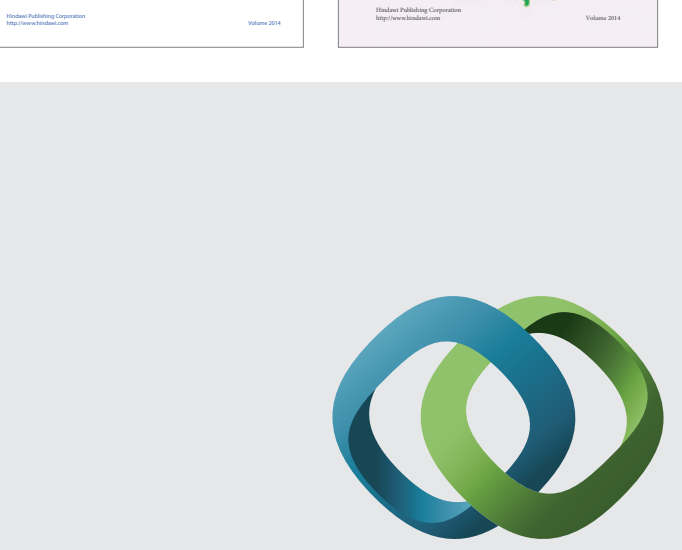

\section{Hindawi}

Submit your manuscripts at

http://www.hindawi.com
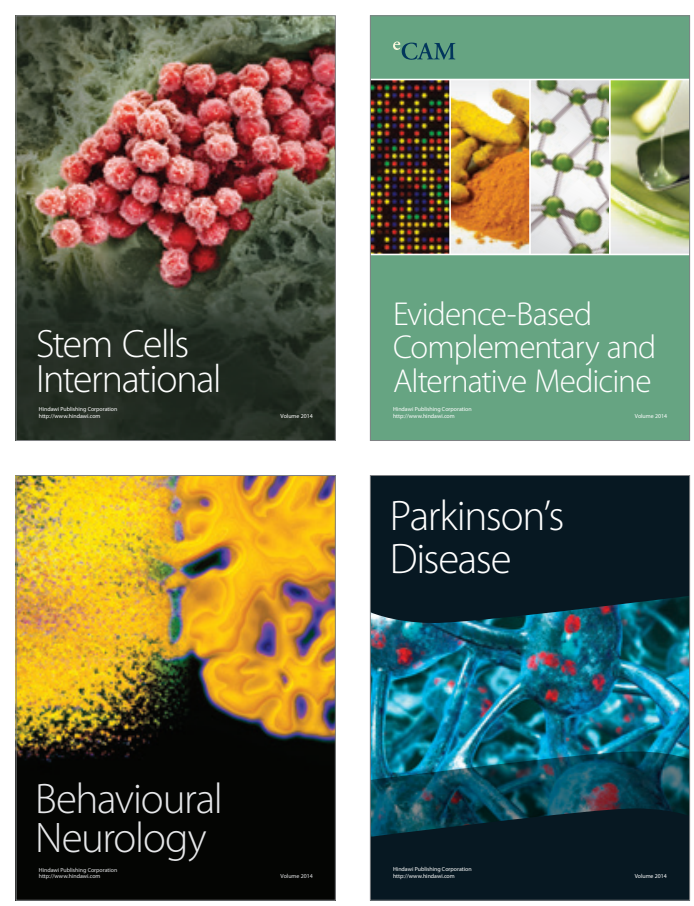

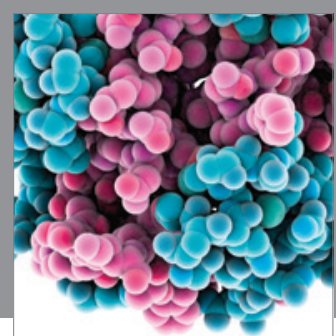

Journal of
Diabetes Research

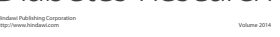

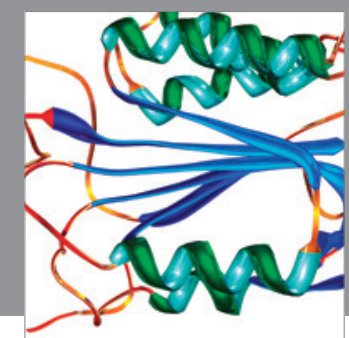

Disease Markers
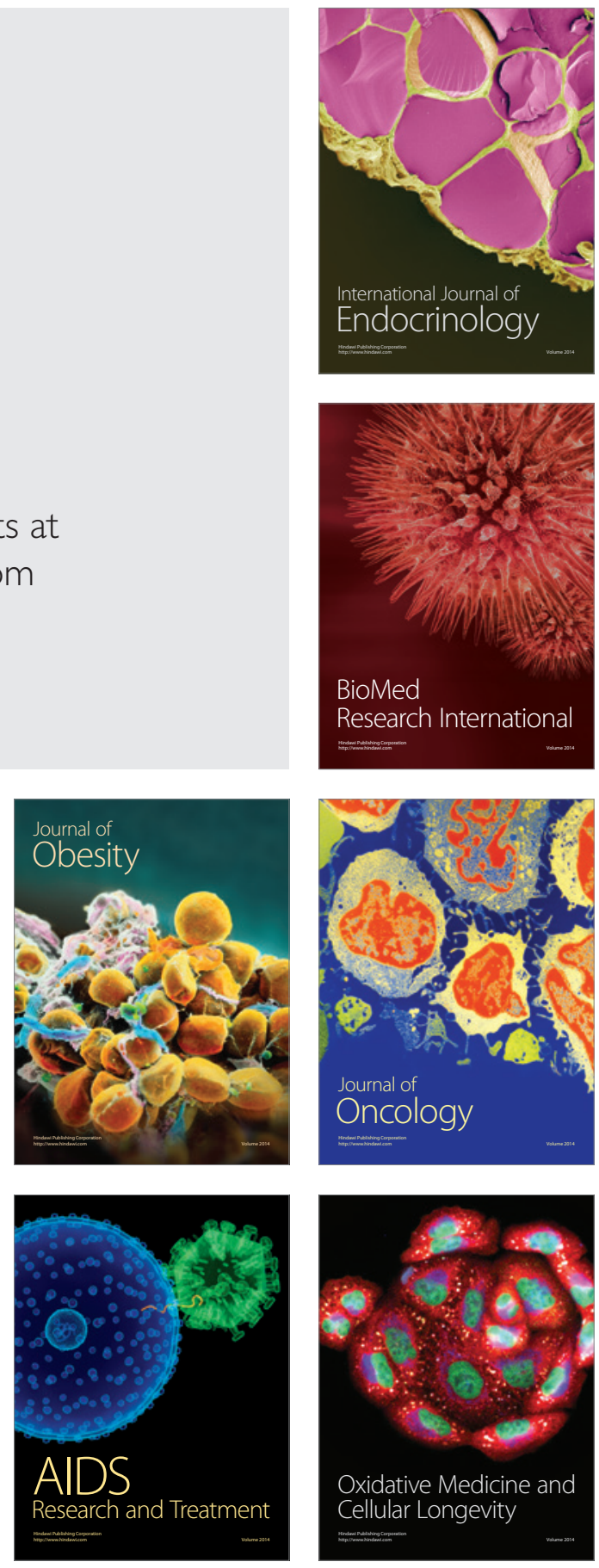